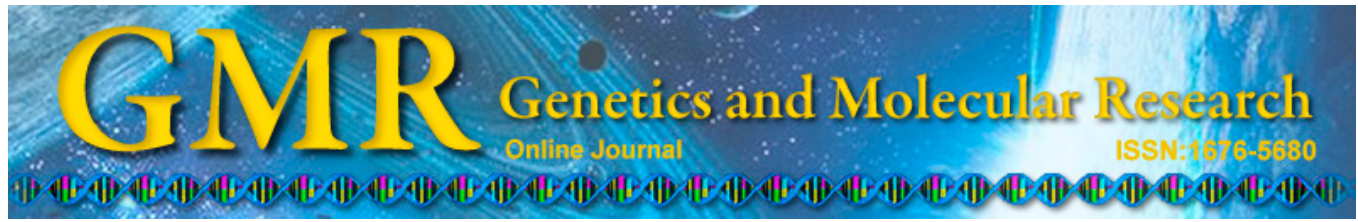

\title{
Development of novel microsatellite markers in the Korean rockfish Sebastes schlegeli
}

\author{
H.-T. Ma ${ }^{1}$, C.-F. Jia ${ }^{1,2}$, J.-M. Yang ${ }^{1}$, F. Wang ${ }^{1}$, R. Xue ${ }^{1,2}$, C.-H. Han ${ }^{1,2}$ and \\ H.-B. Jiang ${ }^{1}$
}

${ }^{1}$ Shandong Provincial Key Laboratory of Restoration for Marine Ecology, Shandong Marine Resource and Environment Research Institute, Yantai, China ${ }^{2}$ College of Fisheries and Life Science, Shanghai Ocean University, Shanghai, China

Corresponding author: H.-B. Jiang

E-mail: haibinjiang326@163.com

Genet. Mol. Res. 14 (2): 5099-5102 (2015)

Received July 4, 2014

Accepted November 25, 2014

Published May 12, 2015

DOI http://dx.doi.org/10.4238/2015.May.12.12

\begin{abstract}
The Korean rockfish Sebastes schlegeli is a valuable recreational and commercial fish in China, and is cultured in land-based tanks and net cages. Fifteen microsatellite markers were developed for this species, and their polymorphisms were examined in a population. The allele number of the 15 markers ranged from 2 to 13 , with an average of 5.933 per locus. The observed and expected heterozygosity values ranged from 0.063 to 0.938 (averaging 0.585 ), and 0.062 to 0.908 (averaging 0.642), respectively. Thirteen loci were at Hardy-Weinberg equilibrium (HWE), whereas the other two significantly deviated from the HWE after a Bonferroni's correction. No significant linkage disequilibrium was detected between the comparisons of these loci. These markers are useful for studies of population genetics, linkage mapping, and other relevant studies on S. schlegeli.
\end{abstract}

Key words: Microsatellites; Polymorphism; Sebastes schlegeli 


\section{INTRODUCTION}

The Korean rockfish, Sebastes schlegeli, of the live-bearing genus Sebastes, belongs to the most species-rich genus of the family Scorpaenidae (Nelson, 1994). It inhabits coastal rocky reefs and feeds on benthic animals, and is generally known as a nonmigratory marine species. This species is a valuable recreational and commercial fish in China, and has been cultured in land-based tanks and net cages, respectively. In recent years, the rising consumption of rockfish products and the decline in natural resources have led to an increase in aquaculture practices and stock transfers of this species. Consequently, stock improvement and resource management are required for the sustainable development of this industry, for both the industrial sector and the scientific community. Microsatellites are a popular marker system for pedigree analysis, genetic linkage mapping, and trait-marker association studies (Zhan et al., 2006; Ma and Yu, 2009; Xiao et al., 2011). Although some microsatellite loci are available for this species (Yoshida et al., 2005; An et al., 2009; Bai et al., 2011; Yasuike et al., 2013), more loci are required for further research. Here, we describe the development and characterization of 15 new microsatellite loci from S. schlegeli.

\section{MATERIAL AND METHODS}

An adductor muscle sample was used to extract genomic DNA, using a standard phenol-chloroform protocol (Sambrook et al., 1989). Approximately $4 \mu \mathrm{g}$ DNA was restricted with Sau3AI, and size fractions ranging from 400 to $1000 \mathrm{bp}$ were recovered from $1.2 \%$ agarose gel using a gel extraction column kit (TaKaRa, Dalian, China). Fragments were then ligated to a blunt-end adapter (SAULA: GCGGTACCCGGGAAGCTTGG, SAULB: GATCCCAAGCTTCCCGGGTACCGC) with T4 DNA ligase (TaKaRa). The ligated fragments were subsequently amplified by polymerase chain reaction (PCR), using SAULA as a primer, before the enrichment of the microsatellite motifs.

A partial genomic library enriched with CA- and GA-microsatellite repeats was constructed using the method described by Carleton et al. (2002). Amplified fragments were denatured and hybridized to a combination of the biotinylated probes (CA) ${ }_{16}$ GCTTGA-Biotin and (GA) ${ }_{16}$ GCTTGA-Biotin, in 6X SSC (saline sodium citrate) $/ 0.1 \%$ SDS (sodium dodecyl sulfate) at $58^{\circ} \mathrm{C}$ for $1 \mathrm{~h}$. The DNA hybridized to the probes was then captured using streptavidin magnetic beads (Dynal, Shanghai, China) and washed. Following purification and elution from the beads, the enriched DNA was denatured in $0.1 \mathrm{X}$ TE at $95^{\circ} \mathrm{C}$ and amplified by post-hybridization PCR using OligoA, and the same cycling program as the pre-hybridization PCR. The DNA was then spin-cleaned, quantified, and TA-cloned into a pGEM ${ }^{\circledR}$-T Easy Vector (Promega, Madison, WI, USA). The vector was subsequently transformed into JM109 competent cells and plated for cloning. Positive clones were identified by PCR using SP6, T7 primers, and $(\mathrm{CA})_{12}$ for CA-repeat or $(\mathrm{GA})_{12}$ for GA-repeat. The positive clones, containing fragments that ranged between $500-900 \mathrm{bp}$ in length, were sent for sequencing.

Forty-five sequences contained microsatellites, and 32 possessed a sufficient flanking sequence that was appropriate for primer design. Twenty-three pairs of primers were designed by the Primer Premier 5.0 program (Premier Biosoft International, Palo Alto, CA, USA). The microsatellite loci were evaluated using a population of 30 individuals collected from Yantai, Shandong Province, China. Primer pairs were amplified in $20-\mu \mathrm{L}$ reactions containing $0.25-$ $0.5 \mathrm{U}$ Taq polymerase (Tiangen, Beijing, China), $1 \mathrm{X}$ PCR buffer, 1.0-2.0 $\mathrm{mM} \mathrm{MgCl}, 0.2 \mathrm{mM}$ 
dNTPs, $0.2-1 \mu \mathrm{M}$ of each primer, and 20-100 ng of total DNA. The PCR conditions were as follows: initial denaturation at $95^{\circ} \mathrm{C}$ for $5 \mathrm{~min}$, followed by 28 cycles at $94^{\circ} \mathrm{C}$ for $40 \mathrm{~s}$, a primer-specific annealing temperature for $40 \mathrm{~s}, 72^{\circ} \mathrm{C}$ for $1 \mathrm{~min}$, and a final extension at $72^{\circ} \mathrm{C}$ for $10 \mathrm{~min}$. A total of 15 primers, which amplified clear and specific products, were selected and labeled with one of three fluorescent dyes (FAM, HEX, or TAMRA; Sangon, Shanghai, China) for polymorphism detection. The size of the PCR products was measured using an ABI PRISM 3130xl Genetic Analyzer (Applied Biosystems) and the GENEMAPPER software (Applied Biosystems). The number of alleles, the heterozygosity, the Hardy-Weinberg equilibrium (HWE), and the linkage disequilibrium (LD) were analyzed using Genepop 3.4 (Raymond and Rousset, 1995). The polymorphism information content (PIC; Botstein et al., 1980) was estimated using PARFEX (v1.0; Sekino and Kakehi, 2012).

\section{RESULTS AND DISCUSSION}

Fifteen polymorphic microsatellite markers were successfully screened in S. schlegeli (Table 1). The allele number of the 15 polymorphic markers ranged from 2 to 13 , with an average of 5.933 per locus.

Table 1. Characterization of 15 microsatellite loci in the black rockfish, Sebastes schlegelii.

\begin{tabular}{|c|c|c|c|c|c|c|c|c|c|}
\hline $\begin{array}{l}\text { Locus/ } \\
\text { Accession No. }\end{array}$ & Primer sequence $\left(5^{\prime}-3^{\prime}\right)$ & $\mathrm{Ta}\left({ }^{\circ} \mathrm{C}\right)$ & Repeat motif & Size range (bp) & $N_{\mathrm{A}}$ & $H_{\mathrm{o}}$ & $H_{\mathrm{E}}$ & PIC & $\begin{array}{l}\text { HWE } \\
\text { P value }\end{array}$ \\
\hline HJ1-21 & F: AGGAGGGAGGAATGGAAA & 60 & $(\mathrm{CT})_{5}$ & $352-376$ & 2 & 0.063 & 0.062 & 0.059 & 1.0000 \\
\hline KM079261 & R: TCAGTAAACGGCTGGTAGG & & & & & & & & \\
\hline HJ5-5 & F: AAACATCACAACAAAGAG & 54 & $(\mathrm{TG})_{24}$ & $258-271$ & 3 & 0.563 & 0.451 & 0.401 & 0.3365 \\
\hline KM079262 & R: TTGCCTGTAAGTATTACA & & & & & & & & \\
\hline HJ5-9 & F: GCCTTTAGATGCTTGTGG & 60 & $(\mathrm{CCT})_{7}$ & $205-233$ & 4 & 0.469 & 0.696 & 0.633 & 0.0375 \\
\hline KM079263 & R: TCTTCTCGTACTCCTCGTC & & & & & & & & \\
\hline HJ5-13 & F: CCCGATTACTGGGAAGAG & 63 & $(\mathrm{GATA})_{3}(\mathrm{GA})_{13}$ & $250-326$ & 13 & 0.906 & 0.908 & 0.885 & 0.7615 \\
\hline KM079264 & R: CTGAGGACAGATGCTGGA & & $(\mathrm{GA})_{10} \mathrm{~T}(\mathrm{AG})_{6}$ & & & & & & \\
\hline HJ5-50 & F: CGCGAGTGATGTTTGAGA & 50 & $(\mathrm{CA})_{6}$ & $214-239$ & 4 & 0.719 & 0.634 & 0.576 & 0.0249 \\
\hline KM079265 & R: CGATTGCCGTAGTTGGTC & & & & & & & & \\
\hline HJ5-62 & F: CTCGGTCACCATAACAAT & 63 & $(\mathrm{CT})_{15}$ & $155-228$ & 11 & 0.781 & 0.857 & 0.829 & 0.0924 \\
\hline KM079266 & R: ACATAGAGCCCAAAACAG & & & & & & & & \\
\hline HJ5-69 & F: ACAGCAGCTTCTACAACTGAA & 50 & $(\mathrm{TCT})_{4}$ & $95-113$ & 4 & 0.156 & 0.179 & 0.171 & 0.2375 \\
\hline KM079267 & R: CAACACTGCGTCACATCAA & & & & & & & & \\
\hline HJ5-79 & F: CCAATGAGCTGGATGTGA & 60 & $(\mathrm{CCTC})_{3}(\mathrm{CCTC})_{4}$ & $328-369$ & 3 & 0.469 & 0.506 & 0.436 & 0.0180 \\
\hline KM079268 & R: AGACGAGGCAGAGCAAGT & & $(\mathrm{CCTC})_{3}$ & & & & & & \\
\hline HJ5-97 & F: TTACGACCCGCCATTAAC & 65 & $(\mathrm{TC})_{19} \mathrm{G}(\mathrm{CT})_{13}$ & $184-267$ & 9 & 0.938 & 0.867 & 0.836 & 0.3679 \\
\hline KM079269 & R: ATCAGCAAAGGGCAACGA & & & & & & & & \\
\hline HJ5-102 & F: GCTTATTGCCAAGACGAG & 60 & $(\mathrm{AG})_{6} \ldots(\mathrm{AG})_{8}$ & $160-193$ & 5 & 0.531 & 0.796 & 0.748 & 0.0136 \\
\hline KM079270 & R: AGTCCGACCAGTATCCAA & & & & & & & & \\
\hline HJ5-111 & F: CACCTTGCCAAGCTCATC & 60 & $(\mathrm{TGA})_{8}$ & $231-272$ & 9 & 0.686 & 0.842 & 0.809 & 0.0678 \\
\hline KM079271 & R: GGTTTCCAGGGTTTCAGA & & & & & & & & \\
\hline HJ5-114 & F: TGACGGGAGTCTTTGACC & 66 & $(\mathrm{AG})_{7}$ & $91-127$ & 6 & 0.937 & 0.753 & 0.700 & 0.0000 \\
\hline KM079272 & R: GAGGAAACACCAAGCACC & & & & & & & & \\
\hline HJ5-116 & F: GAAAGGCAGGAACCAAAC & 52 & $(\mathrm{CTAA})_{6}$ & $132-164$ & 8 & 0.688 & 0.841 & 0.806 & 0.3116 \\
\hline KM079273 & R: GTGATGTGAAGGAGACCC & & & & & & & & \\
\hline HJ5-123 & F: GGCAGCCTGGAGAATAAC & 50 & $(\mathrm{TC})_{18}$ & $150-171$ & 4 & 0.250 & 0.494 & 0.447 & 0.0000 \\
\hline KM079274 & R: GAAACCTGGAGCAGAACC & & & & & & & & \\
\hline HJ5-139 & F: TCCGTAACGTGAACCATG & 60 & $(\mathrm{CTG})_{4} \ldots(\mathrm{CA})_{19}$ & $344-375$ & 4 & 0.625 & 0.744 & 0.683 & 0.2759 \\
\hline KM079275 & R: GCAGAAGGCTCAGCAGTT & & & & & & & & \\
\hline
\end{tabular}

$\mathrm{F}=$ forward primer; $\mathrm{R}=$ reverse primer; $\mathrm{Ta}=$ annealing temperature; $N_{\mathrm{A}}=$ of alleles; $H_{\mathrm{o}}=$ observed heterozygosity; $H_{\mathrm{E}}=$ expected heterozygosity; PIC = polymorphic information content; $\mathrm{HWE}=$ Hardy-Weinberg equilibrium. 
Four loci were at a medium or a medium-high level of polymorphism in terms of the number of alleles $(\geq 9)$. The locus HJ5-13 was the most polymorphic, with 13 distinct alleles, whereas the locus HJ1-21 was the least polymorphic, with two alleles.

The observed heterozygosity varied from 0.063 to 0.938 , with an average of 0.585 , while the expected values for these loci ranged from 0.062 to 0.908 , with an average of 0.642 . In addition, the PIC ranged from 0.059 to 0.885 , with an average value of 0.601 . Thirteen loci exhibited medium, or medium-high, levels of polymorphism in terms of PIC $(>0.25)$. After a Bonferroni's correction, exact tests for the HWE revealed that 13 of the 15 markers accorded with the equilibrium, but the rest exhibited significant departures from the HWE. No significant LD was detected between the comparisons of these loci. These markers should be useful in population genetics, pedigree analysis, linkage mapping, and other relevant studies on $S$. schlegeli.

\section{ACKNOWLEDGMENTS}

Research supported by the Program of Agriculture Thoroughbred Project, Shandong Province, China, the Program of China Agriculture Research System (\#nycytx-50), and the Municipal Scientific Developing Project of Yantai (\#2013ZH088).

\section{REFERENCES}

An HS, Park JY, Kim MJ, Lee EY, et al. (2009). Isolation and characterization of microsatellite markers for the heavily exploited rockfish Sebastes schlegeli, and cross-species amplification in four related Sebastes spp. Conserv. Genet. 10: 1969-1972.

Bai CC, Liu SF, Zhuang ZM, Lin L, et al. (2011). Isolation and characterization of microsatellite markers for the Korean rockfish, Sebastes schlegeli. Genet. Mol. Res. 10: 2065-2068.

Botstein D, White RL, Skolnick M and Davis RW (1980). Construction of a genetic linkage map in man using restriction fragment length polymorphisms. Am. J. Hum. Genet. 32: 314-331.

Carleton KL, Streelman JT, Lee BY, Garnhart N, et al. (2002). Rapid isolation of CA microsatellites from the tilapia genome. Anim. Genet. 33: 140-144.

Ma HT and Yu ZN (2009). Development of twenty-two polymorphic microsatellite loci in the noble scallop, Chlamys nobilis. Conserv. Genet. 10: 1587-1590.

Nelson JS (1994). Fishes of the world. 3rd edn. John Wiley and Sons, New York.

Raymond M and Rousset F (1995). Genepop (version 1.2): population genetics software for exact tests and ecumenicism. J. Hered. 86: 248-249.

Sambrook J, Fritsh EF and Maniatis T (1989). Molecular cloning: a laboratory manual. 2nd edn. Cold Spring Harbor Laboratory Press, Cold Spring Harbor.

Sekino M and Kakehi S (2012). PARFEX v1.0: an EXCEL ${ }^{\mathrm{TM}}$-based software package for parentage allocation. Conserv. Genet. Resour. 4: 275-278.

Xiao S, Ma HT and Yu ZN (2011). Development of 20 novel microsatellite markers in the Hong Kong oyster, Crassostrea hongkongensis. Conserv. Genet. Resour. 3: 413-415.

Yasuike M, Noda T, Fujinami Y and Sekino M (2013). Tri-, tetra- and pentanucleotide-repeat microsatellite markers for the Schlegel's black rockfish Sebastes schlegelii: the potential for reconstructing parentages. Conserv. Genet. Resour. 5: 577-581.

Yoshida K, Nakagawa M and Wada S (2005). Multiplex PCR system applied for analyzing microsatellite loci of Schlegel's black rockfish, Sebastes schlegeli. Mol. Ecol. Notes 5: 416-418.

Zhan AB, Bao ZM, Yao B, Wang XL, et al. (2006). Polymorphic microsatellite markers in the Zhikong scallop Chlamys farreri. Mol. Ecol. Notes 6: 127-129. 